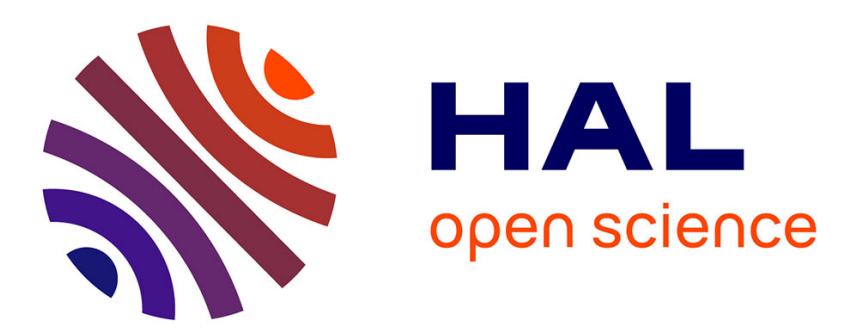

\title{
Innovative Product and Network of Partners Co-design: Context, Problems, and Some Exploratory Results
} Marc Zolghadri, Claude Baron, Philippe Girard

\section{To cite this version:}

Marc Zolghadri, Claude Baron, Philippe Girard. Innovative Product and Network of Partners Codesign: Context, Problems, and Some Exploratory Results. Concurrent Engineering: Research and Applications, 2008, 16 (1), pp.9-21. 10.1177/1063293X07084635 . hal-00571213

\section{HAL Id: hal-00571213 \\ https://hal.science/hal-00571213}

Submitted on 1 Mar 2011

HAL is a multi-disciplinary open access archive for the deposit and dissemination of scientific research documents, whether they are published or not. The documents may come from teaching and research institutions in France or abroad, or from public or private research centers.
L'archive ouverte pluridisciplinaire HAL, est destinée au dépôt et à la diffusion de documents scientifiques de niveau recherche, publiés ou non, émanant des établissements d'enseignement et de recherche français ou étrangers, des laboratoires publics ou privés. 


\title{
Innovative Product and Network of Partners Co-design: Context, Problems, and Some Exploratory Results
}

\author{
Marc Zolghadri, ${ }^{1, *}$ Claude Baron ${ }^{2}$ and Philippe Girard ${ }^{1}$ \\ ${ }^{1}$ IMS Laboratory, Bordeaux University, F-33405 Talence, France \\ ${ }^{2}$ LATTIS, University of Toulouse, F-31077 Toulouse, France
}

\begin{abstract}
Innovative product development and in-house process design have been largely studied and methods, such as concurrent engineering, integrated product development, or dynamic product development are set up to answer real needs of industrialists. However, no innovative product can be put on the market without a well-structured and well-organized network of partners. This simple idea deeply influences various aspects of collaborative enterprises. This article studies the close relationship between two parallel design processes: product design and network design. This paradigm called co-design is explained and some basic concepts and exploratory results are defined.
\end{abstract}

Key Words: product development, co-design, added value, network of partners.

\section{Introduction}

\subsection{Design for Manufacturing Manageability}

Firms look for a sustainable positioning on the global and local market. They define their business objectives and a roadmap to achieve them. This task is harder to perform for small and medium enterprises (SMEs) than big groups, mainly because of their constraints in terms of limited technical, human, and financial resources. Therefore, firms need to work with partners. But, one understands intuitively that collaboration is a risky game [1], especially for SMEs exactly due to their higher limitations. It means that the question of collaboration remains one of the fundamental problems of firms.

Another basic observation can be made. Firms look for higher and higher competitiveness day after day. This search of competitiveness can be qualified by one aggregated attribute: the firm's capability to put on the market innovative products. This concept is referred to as the innovation-achievement capability. It highlights the capability of a firm to introduce an innovative product on the market by innovating at least in one of the following aspects: technological processes, organization, or management.

The firm's innovation-achievement capability should be robust, i.e., does not vary easily as the firm's

*Author to whom correspondence should be addressed.

E-mail: Marc.Zolghadri@laps.ims.bordeaux.fr

Figures 1-8 appear in color online: http://cer.sagepub.com parameters change. However, by focusing on the external environment of a firm and its partners, it is found that this capability is influenced directly by many crucial parameters, such as collaboration principles, objectives, and (necessary and sufficient) data exchange protocols. These parameters are numerous, sometimes uncontrollable and especially not all of them are known at the beginning of a collaborative project. This makes the situation complex for managers and the innovationachievement capability hard to control. This idea is also underlined in Johnson et al. [2] and Hax and Majluf [3]. This is especially the case of those firms that look for innovative products and need the close collaboration of partners in almost every phase of the product life cycle: market study, create, make, sell, and distribute goods. This study deals with methods that improve the innovation-achievement capability of firms.

Researches in many fields target at helping managers before, during, and after any collaborative project. Fields, such as industrial engineering, design science, and management science for instance have already provided important results. However, since the beginning of 1990s some new efficiency niches were discovered; especially the three-dimensional concurrent engineering defined by Ch. Fine [4] (See Section 2 for more details).

At the same time in Europe, academics and industrialists worked on the same area. For instance, early at the beginning of 2000, a three-years ESPRIT project, DRAGON, with China was funded by the European Union. The authors participated in this project. The main idea of this project was to allow 
European firms to find new collaborators in China through a web-based portal. This portal has two inputs:

1. A firm $X$ defines its needs in terms of technology or components by providing specificities.

2. Potential partners answer these requirements. They have to add some information about the way they are able to collaborate with $X$.

The portal allows then to match needs and offers. Somehow, the portal supports firms in their first steps towards unknown and potential partners.

These ideas, together with other results related to research, show that the joint design of products and the network of partners could represent a potential source of higher efficiency.

The way companies are 'forced' to consider the co-design paradigm is described here. Figure 1 shows a very simplified and self-explanatory causal diagram which shows that any need of an innovative product could conduct towards collaboration with partners. And these collaborations will impose more or less hard constraints on the company. This causal diagram can be translated to the following axiom 'No efficient network No (innovative) products'. By talking about efficient network, reference is made not only to its architecture (the way that partners are connected together) but also to its parameters (the network's run).

The co-design problematic is too wide to be studied as a whole. Hence, the context is narrowed to a specific kind of situations detailed hereafter.

\subsection{The Study Focus}

The considered collaboration situations, with known or new partners, are generated by the will of innovation of one focal company (FC). This company is responsible for the product (a car manufacturer for instance) and should work with other companies for some specific parts (engine or dashboard). Some of the FC's partners will contribute not only to the manufacturing of components but also to their design. To be able to collaborate efficiently with its partners, the FC has to negotiate with each one. These negotiations are guided, in general, by a strategic diagnosis of (a) external environment, through the identification of opportunities and threats, and (b) internal environment through the determination of strengths and weaknesses (see [2,3]).

In a classical way of doing business, with these elements in hand the FC finds potential partners, evaluates them, selects the most appropriate ones, negotiates with them, and finally signs contracts with chosen partners. The real co-working begins just after, during the product design and manufacturing of items. And it corresponds to the toughest challenge for any collaboration because of the short profitability period of innovative products threatened by imitated or concurrent products.

But, it is seen that the analysis phase, design phase, and do phase of collaborative project have more complex relationship together. The product design is influenced by the network attributes and vice versa. Somehow, it is claimed that the FC managers have to

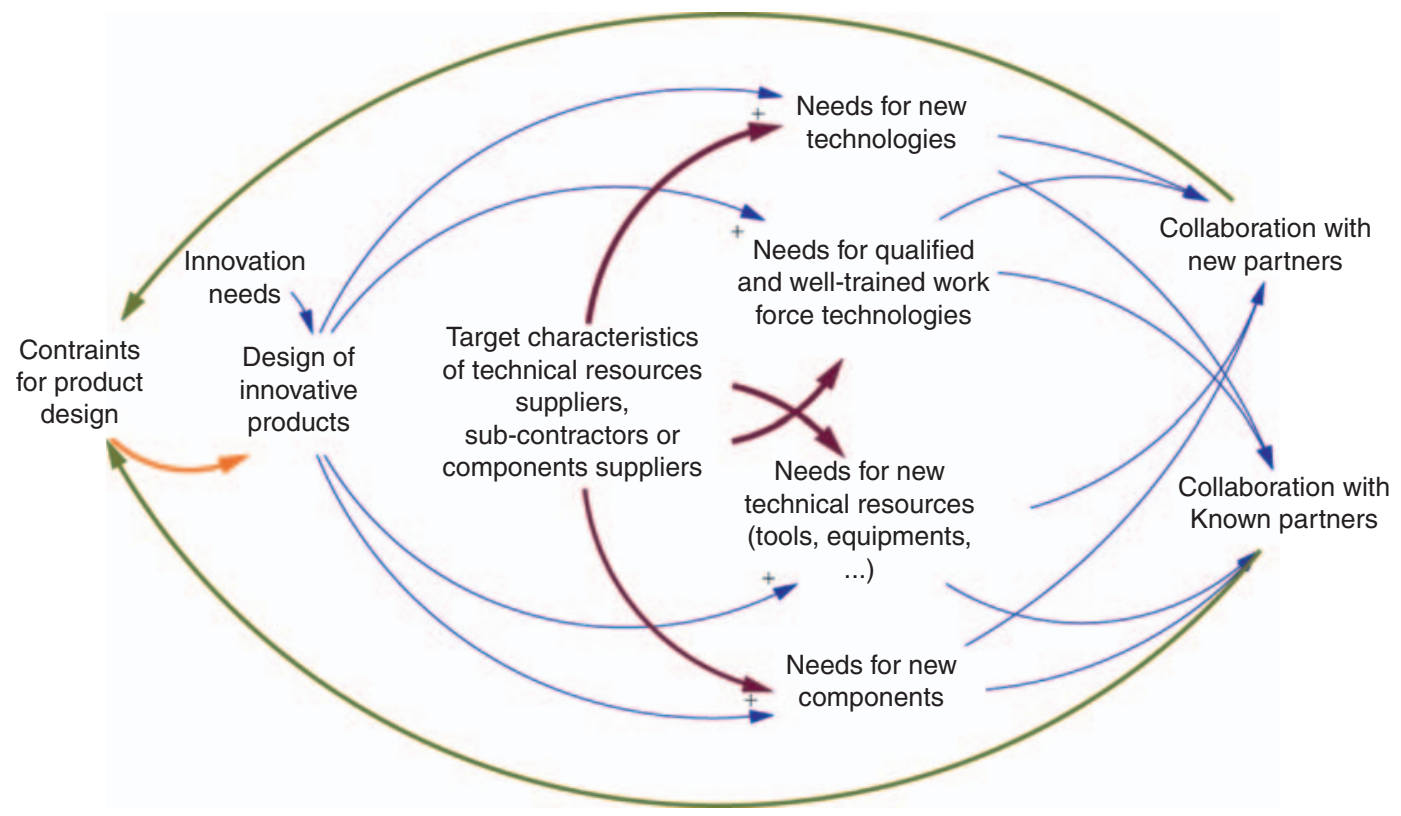

Figure 1. Causal diagram of co-design collaboration needs. 
choose their most relevant partners not only from the product design perspectives but also from the 'manufacturing manageability' point of view and this forms the beginning of the innovation project!

The rest of this article is organized as follows. The next section puts the basis of the topics of this study. A state-of-the-art of collaboration contexts is given. The aim is to cover product design from one side, value network design on the other and finally some pioneering works considering product design and value network design simultaneously are reported. This section will allow a re-formulation of the objective of this study. Characteristics of the so-called co-design paradigm are then clarified in Sections 3 and 4. Section 5 defines the co-design life cycle and focuses briefly on the control aspect of co-design. The results are discussed then and research perspectives are explained at the end of the article.

\section{The State-of-the-art}

\subsection{Various Facets of Innovation}

Innovation is referred to, as suggested by Ottosson [5], by the definition of the Organization for Economic Co-operation and Development, as a concept which takes account of products, processes, and organization, in Oslo Manual (1997) 'Technological product and process (TPP) innovations comprise implemented technologically new products and processes and significant technological improvements in products and processes ...'

The co-design paradigm is concerned by two product innovation classes, classically mentioned in the scientific literature: radical or incremental. In the case of incremental innovation, product development objectives and process are well-known; the uncertainties are 'small'. The company's partners (suppliers, subcontractors) may contribute, directly or indirectly, to the design and manufacturing of the product by offering components or technologies. In this case, the product design process is 'easy' or at least it is done routinely. For radical innovative products, the uncertainty is much more important. The development process is known just globally or more or less roughly and the results of design activities are not completely known. The product design process is complicated.

In both cases, the need of co-design considerations depends somehow on the uncertainty level. The more the uncertainty, the more the co-design considerations.

\subsection{Design Frameworks}

\subsubsection{NETWORK DESIGN AND MANAGEMENT}

Various works have been done in the scope of network design (see for instance [6-11]). Beamon [6] classified these works into four modeling paradigms: deterministic analytical models, stochastic analytic models, economic models, and simulation models. These works mainly answer the geographical positioning of various partners of the network. He defines several performance measures for the network design: (a) qualitative, such as customer satisfaction and flexibility or (b) quantitative like cost. Garg [12] looked for a tactical/strategic level processproduct design. Wang et al. [13] and Geunes and Pardalos [14] worked on the choice of relevant suppliers. Techniques, such as analytic hierarchy process and various mathematical programming are commonly used. Specially, Geunes and Pardalos [14] provided an interesting survey of supply chain (SC) design works and underlined that this problem could be studied from strategic, tactical, and operational points of view. They gathered results from industrial applications too, but does not consider the product design. Gunasekaran and Ngai [11] studied build-to-order SC, precisely defined this concept, and provided an extensive literature review. Nevertheless, they did not mention the innovative product collaborative design. Hicks et al. [15] studied this context and argued that there could be an efficiency niche for consideration of strategic trends in SC design for early product design. Harrison [16] distinguished the SC problems into two inter-connected areas: SC design and SC execution. Again, he did not consider the question of product design during the design of the SC.

\subsection{2 (COLLABORATIVE) PRODUCT DESIGN}

Design process commonly defines activities which characterize the evolution of product knowledge from customer's attendees to customer's satisfaction. This process is generally constrained by design objectives (customer requirements on product definition) or by enterprise organization [17] and are influenced by technologies or human and physical resources $[12,18]$. Many research works focus on design methods which model design process (i.e., designers' activities during different steps of the product life cycle). Different models, used to represent engineering processes, have been proposed in the scientific literature [19]. Perrin [20] classified those models into five categories: succession of hierarchical steps [21], iteration of an elementary design cycle [22,23], emergent phenomenon of self-organization [24], cognitive process [25], communication, and interactive mode [26,27]. Pahl and Beitz [21] and Ullman [28] proposed to characterize the product development life cycle (activities composing the design process) at the highest level of abstraction by four steps: clarification of tasks, conceptual design, embodiment, and detail design.

Ullrich in his book [29] proposed process flow diagrams for various product development processes. Whatever the complexity of these models is, he distinguished planning, concept development, system-level 
design, detail design, testing and refinement and final production rump-up.

The design works taken separately from product and network fields show some nascent interests concerning the co-design of product and network of partners. Hereafter, some of the most important works that were found in the literature where both fields are considered simultaneously are described.

\subsubsection{PRODUCT AND NETWORK DESIGN}

To study co-working, interactions between product design and its management from one side and network design and its management from the other are considered. Vonderembsea et al. [30] resumed the design of supply chain as an issue of product design: 'Supply chain design should be, in part, a function of the product characteristics and expectations of the final customer (see for instance [9,24]).'

The idea of simultaneous design of product, process, and supply chain, based on this research, was first proposed by Prof. Charles H. Fine [4]. He proposed the concept of clockspeed which covers the evolution rate of industries. In this book, Fine shows that the conjunction between these design activities forms a fundamental element to ensure business success. The global framework is named three-dimensional concurrent engineering, 3D-CE. It proposes a method, called double helix, to define the firm's strategy based on its relationships with suppliers, customers, and its market position. Fine mentioned successful applications of his method for patient monitoring division of Hewlett-Packard and at Teledesic.

Focusing on product design and the way that it influences the supply chain design, Fisher [31] distinguishes two categories of product: primarily functional or innovative. He shows that the supply chain depends directly to the category of the products. Related to the category of products, Fisher underlines two cost categories: physical cost (transformation of raw materials) and market mediation cost (ensure that the products manufactured in supply chain correspond to the needs of customers). In the case of manufacturing of functional products, managers can be and are, in general, focused on physical cost optimization. For innovative products, they have to be focused on market mediation costs which are harder to control. Less scientific works are available in this latter field. He also proposes tools necessary for a manager to define whether the firm's products belong to functional or innovative. An interesting point that Fisher reveals is that sometimes due to the product strategy, the product category moves slowly from functional toward innovative while the supply chain remains almost the same. This latter case, according to him, could push companies towards catastrophic business situations.

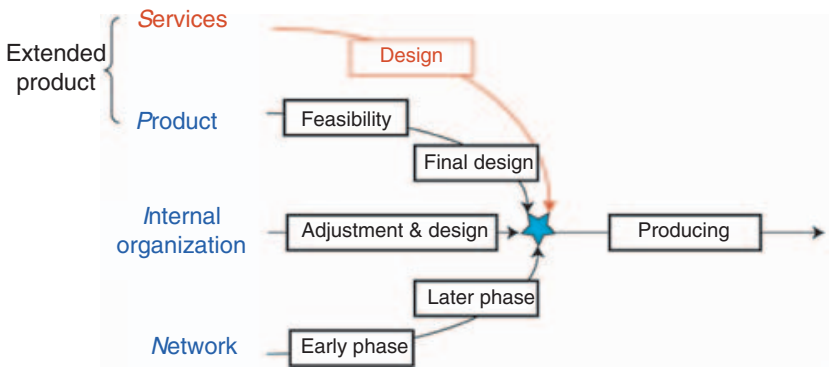

Figure 2. The SPIN model.

These works represent the pioneering works done in this field showing that as the economical and business situations become more and more complex, the joint design of product, process, and external organization could represent a new success potentiality for firms.

\section{The SPIN Model for Co-design Paradigm}

\subsection{Services, Product, Internal Facilities/ Processes, Network of Partners}

A model is proposed to capture the globality of the design tasks. This model is depicted in Figure 2 and represents a pitchfork with at most four prongs. It takes account of four design parallel processes: Services associated with the product, the Product itself, the Internal facilities and processes, and finally the Network of partners.

The first two prongs of the SPIN model gather elements of an extended product (a product with associated services such as hotline, training, etc.). If in a given situation, services are not considered the fork would have just three prongs. The internal organization of facilities and processes of the firm should be (re-)designed to ease the products' manufacturing (this is the subject of concurrent engineering). Finally, the network of partners should be designed or re-designed to allow or to ease the collaborative design and manufacturing of the product. Each prong corresponds to the design part of the considered item and the blue star illustrates the fact that once all of these items are designed (inputs) or re-designed the manufacturing of the product can be started (outputs).

The control and supervisory activities of the SPIN model is represented in Figure 3. The idea is that the control and supervisory activities are necessary to conduct the overall system and each of the four processes, design as well as the manufacturing processes. This control and supervisory system are detailed in Section 5.

As the study reported here refers to the products and the network of partners, it is noted $\mathrm{P}-\mathrm{N}$ for short. 


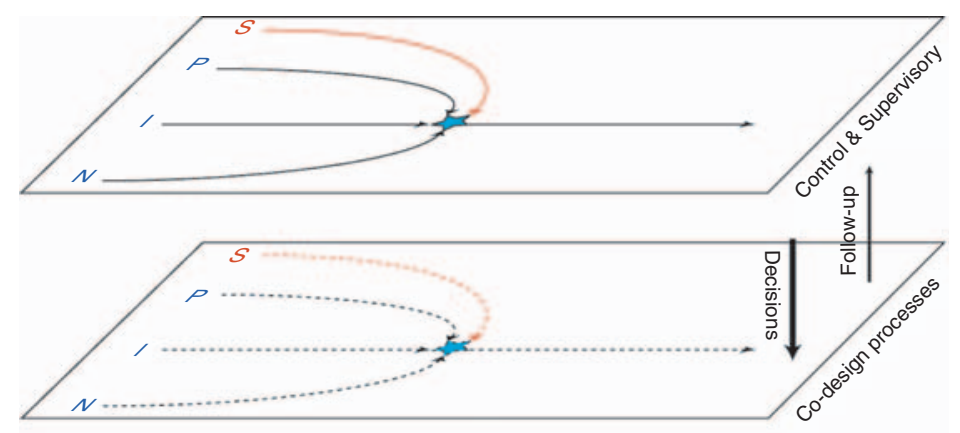

Figure 3. Control and supervisory processes.

The objective of any $\mathrm{P}-\mathrm{N}$ study is to understand the way by which these two design processes influence each other and how they should be synchronized.

Every decision made regarding the design of a product will influence more or less the way the network of partners should be designed, managed, and supervised/ controlled. On the other hand, every network design parameter could influence the product design orientations during steps, such as concept development (see [29]). Section 5 discusses these mutual dependencies.

\subsection{Design Product while Keeping in Mind the Network of Partners}

The second phase of a generic development process according to Ullrich [29] is concept development. During this phase, alternative product concepts are generated and evaluated. One or more concepts are selected for further development and testing. The system-level design includes the definition of the product architecture and the decomposition of the product into subsystems and components. Finally, the detailed design phase includes the complete specification of the geometry, materials, tolerances, of all of the parts in the product and the identification of the standard parts to be purchased from suppliers.

These tasks are fulfilled based on internal and external search of solutions and expertise. The external search of knowledge as suggested by Ullrich can be used by interviewing experts or consulting patents. During these successive phases, the whole product is designed, especially in terms of its building blocks and the architecture. One may see intuitively that these elements are closely related to the network of partners and the way business negotiations were carried out with them. This idea is deeply looked into here.

\subsubsection{THE BUILDING BLOCKS}

A product can be seen as a composition of building blocks. A building block can be viewed as the output of a design activity or a process. Modeled by an activity (for example IDEF0 formalism), complementary elements should be defined too: inputs, knowledge and control mechanisms, supporting resources. Now, the partners of the FC are presented.

The reason why a firm chooses to work with a partner is that it has to procure inputs, necessary knowledge (to execute the activity or the process), or resources. Therefore, when designers want to choose some product concepts (Ullrich model), they:

1. should know their firm's capabilities in terms of activity execution and its elements: inputs, knowledge, and support resources, and

2. have to know as clearly as possible what can be really expected from the market in terms of inputs, knowledge, and resources.

The very first thought of every designer is to answer the functional specifications and to find out whether a building block can be made in-house or not. If not, what kind of help do they need: (1) the partners' help in terms of inputs; this is the role of suppliers, (2) knowledge; this is done by consultancy and expert centers, or (3) support resources; this is done by sub-contractors or technology suppliers.

Clearly, it means that choices of the way that partners should collaborate with the FC are necessarily oriented by product designers' ideas about the building blocks. It is necessary but not sufficient. The complete definition of a product includes the product architecture too.

\subsubsection{THE ARCHITECTURE}

During the concept development phase, engineers answer the very classical question of 'make or buy' for every building-block. Two classes of items can be roughly distinguished for every single block: in-house made item (make) or out-house item (buy). Any building block may be composed of components belonging to these two classes. The out-house items which define synchronization situations with partners are focused here. Furthermore, the architecture of the product or the order of the assembly of building blocks gives one information to define more precisely an ordered set of synchronization situations with partners. 
The synchronization situations mean long-term, midterm, and short-term potential bottleneck-like problems with partners. At the strategic level, supplying of any out-house item would mean that one new partner should contribute to the development first and to the manufacturing then. At the mid-term and short-term, it means that the product design management system and the manufacturing management system have to take account of explicit constraints (anticipative attributes of the collaboration, such as the quality of made items) and also implicit constraints (hardly defined and therefore controllable aspects of collaboration) of every single supplier of these out-house items. It is therefore clear that the architecture of a product and therefore the decisions made concerning the in-house and out-house items can modify the complexity of synchronization situations. One of the greatest issues of the co-design paradigm is to study and model these connections and provide recommendations for both engineers (for their design tasks) and managers (for their negotiation and collaboration tasks with partners).

\subsection{Design the Network of Partners while Keeping in Mind the Product}

Two network design levels are defined: gross-coarse and fine-coarse. Gross-coarse design concerns strategic design orientations. It corresponds to contact establishment, business discussions, choice of partners, definition of partners' dependencies, definition of exchanges protocols, and so on while fine-coarse design is focused on precise determination of stocks, retailers, best level of goods transportation, etc.

Methods and tools that can be used to support finecoarse design decisions are quite numerous, such as optimization techniques. But the gross-coarse design activities are still fuzzy because before making any product decision one shall take account of internal and external parameters in order to choose the most relevant partners (which microprocessor to choose for a com puter maker for instance).

The mutual influences between product and network design processes are more precisely modeled in the next section.

\section{Co-design Models and Parameters}

\subsection{IDEF0 Models of Network Design}

Three IDEF0 models of this phase are presented in Figures 4-6. These models allow determining the way that the product designers have to interact with the network design team.

The main activity is 'to structure the value network'. It is decomposed into five sub-activities ( $c f$. Figure 5):

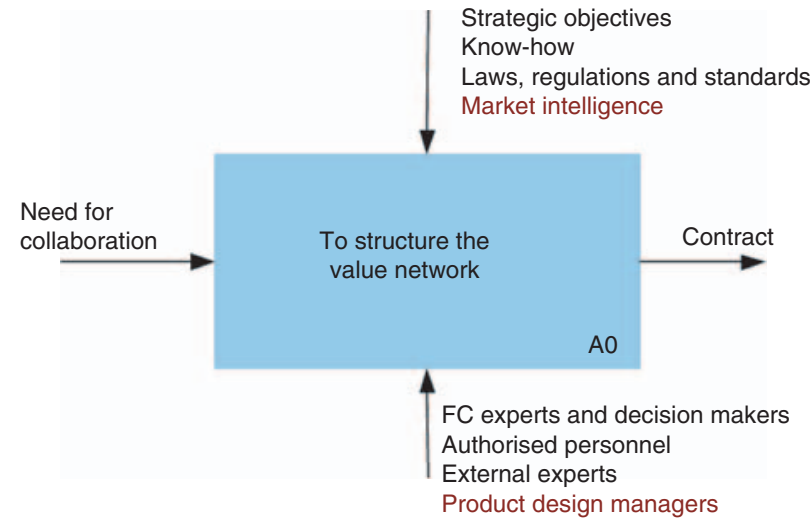

Figure 4. IDEFO model of the network design.

to define requirements, to select potential partners, to negotiate, to select partners, and to sign contract. As partners' selection is focused, four more detailed activities are distinguished within the activity 'to select potential partners' (see Figure 6). They are: to source partners, to evaluate sourced partners, to identify potential partners, and to initiate contact and make first arrangements.

In all these models, one should remark two elements related to the product design: product design managers as additional support resources for the network design process and the product's constraints as additional mechanism and knowledge necessary for this process. These connections will be described more, but before, it is interesting to see what kind of relationships the FC could have with its partners.

\subsection{Partners' Implications}

To characterize various co-design paradigms a taxonomy is proposed based on two criteria: nature and class of relationships, and criticality of relationships.

\section{Classes of relationships}

Interactions with banks, government (legislation), and insurance companies are not considered. Interactions can be then split-up into two generic classes:

a. Sub-contracting: It brings knowledge and/or support resources to the design process. It means that an activity or a process is done by a partner using items which belong to the FC. Various activities can be sub-contracted: Research and development, marketing, distribution, etc.

b. Supplying: It means that a component is sold by a partner.

\section{Classes of partners' co-working}

a. Makers are designers. The designers of building blocks will make them too: a motor producer can 


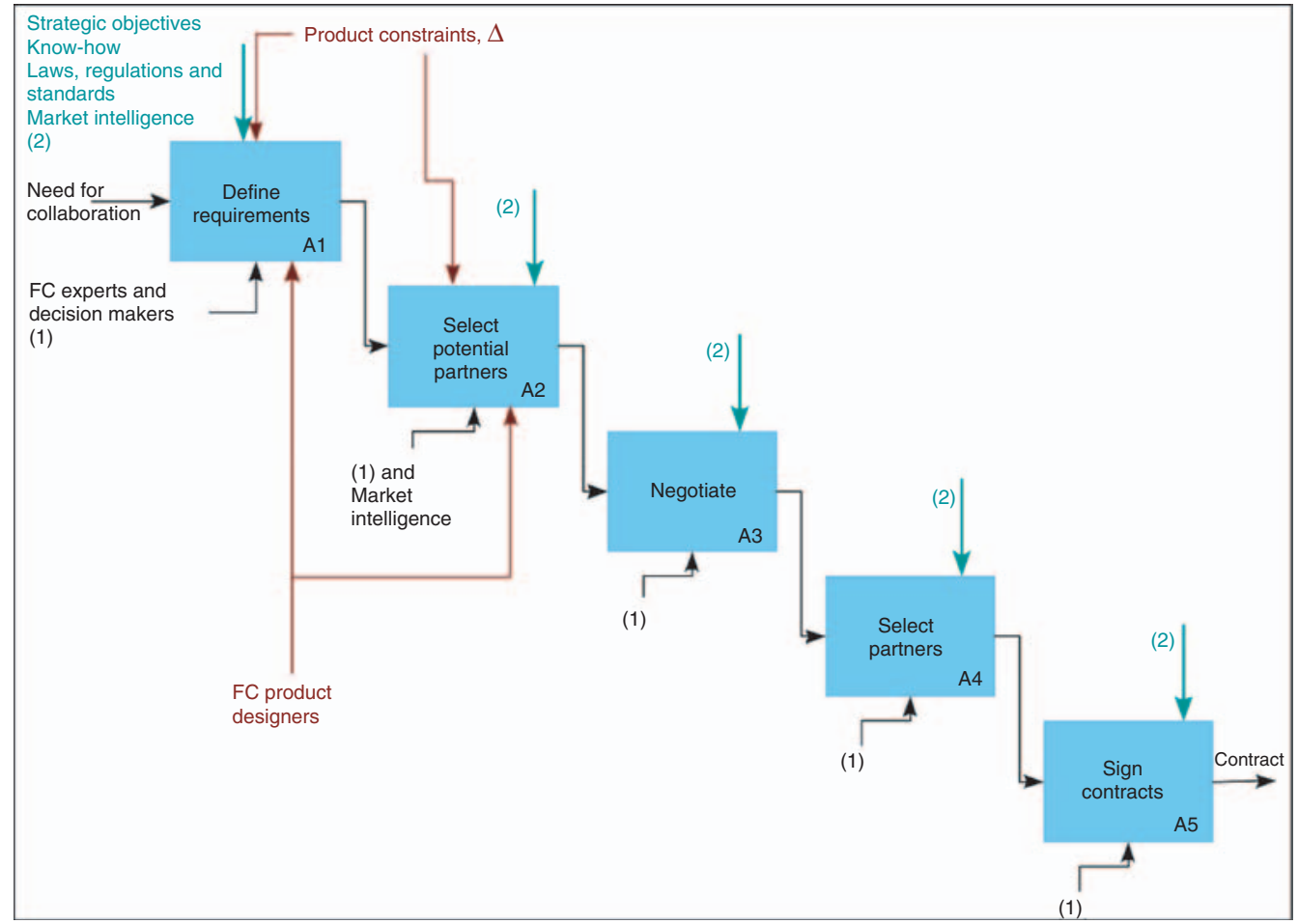

Figure 5. IDEFO model of the network design.

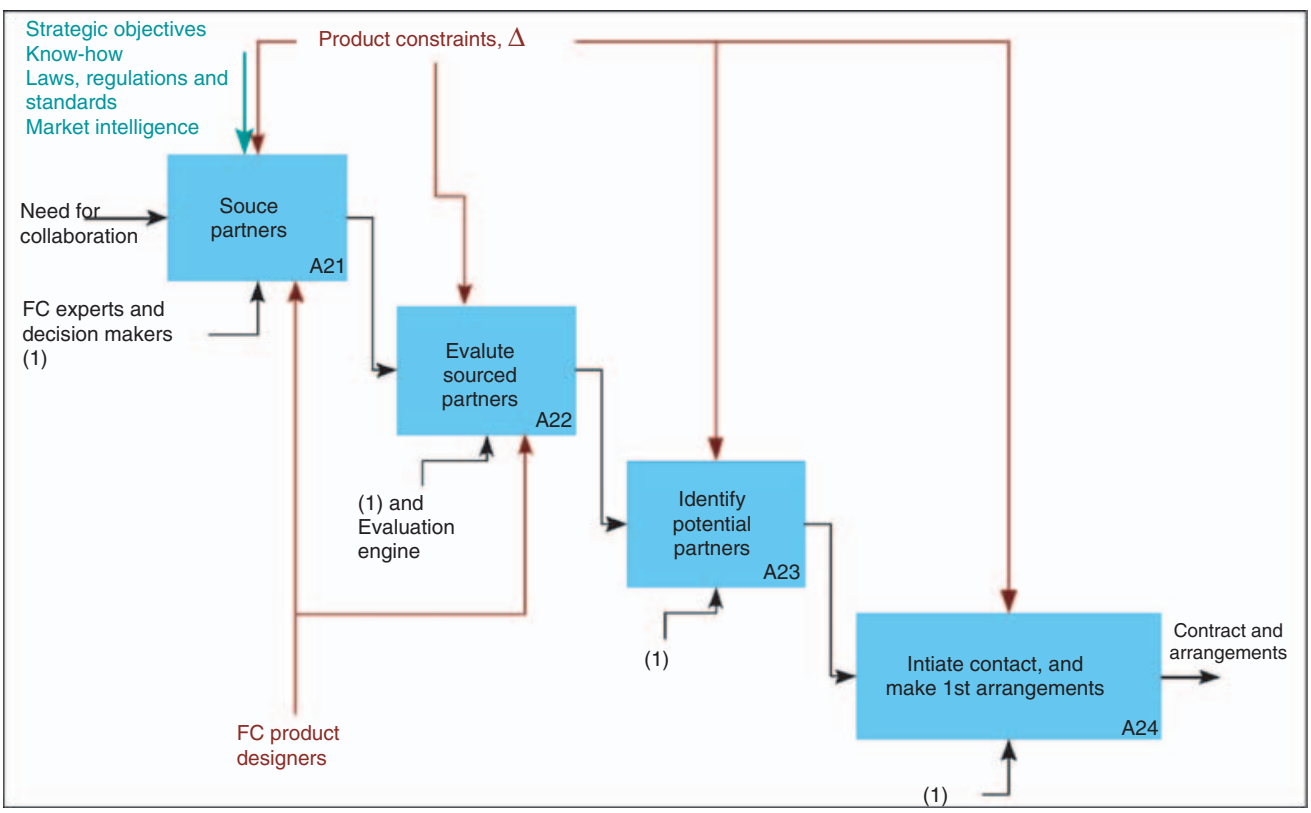

Figure 6. IDEFO model of the network design.

contribute to the development of a new car from the beginning of the project.

b. Makers are not designers. The building blocks' makers are not their designers.
A fundamental problem depending on these two classes is related to data sharing. When a partner contributes to the design phase (i.e., collaborative design activities), the data sharing has simpler terms because of 
its implication from the very first steps of design (synchronously or asynchronously with the FC).

\subsection{Criticality of Partners' Relationships}

At every step of the design process, two categories of partners are distinguished:

- Critical partners. They have direct influence on technical, technological, and functional aspects of products and their participation in the design process is considered as fundamental by the FC. They influence tactical orientation of product design (shape, color, dimensions...) within the framework of the strategic orientations (cost, quality ...) fixed by the FC top staff.

- Support partners. These partners do not have deep influences on the product design process, at that considered design step. Therefore, their specificities are not taken into account for the considered phase. Screws suppliers during the gross-coarse design phase may be considered as support partners.

Nevertheless, partners may change the category, as the design process evolves and the design uncertainties become smaller. Actually, the network architecture evolves as the product design progresses. The critical and support partners are defined according to their influence level on product design or make. At the beginning of the collaborative project, the context is unclear from the product and network points of view. On this account, the focus is put on the most important partners who greatly influence the product's design at this stage. As time goes on, by knowing better and better the context, product, and network specificities, it would be possible to take account of less critical partners. In other words, once the fundamental technological orientations of product is defined the analysis will focus on more detailed aspects of the product design.

The situation is the same once the manufacturing phase is launched because the criticality of partners is modified regarding the objective of the activity (management point of view). Then, a sub-contractor, which was considered as a support partner during the gross-coarse design phase could become critical during the fine-coarse phase.

Based on this taxonomy, in this study the considered classes of partners represent: suppliers and sub-contractors. They are designers and makers of building blocks and correspond to the critical partners of the FC.

\section{The Co-design Spiral life Cycle and its Constraints}

The global life cycle of any $\mathrm{P}-\mathrm{N}$ co-design project is depicted in Figure 7. As can be seen, there should be as iterations as necessary between $\mathrm{P}$ and $\mathrm{N}$ prongs of the SPIN model. Along iterations, mutual constraints are transferred from one prong to the other (one design process to the other). It is suggested to formalize them all by specifications books. In fact, four results are provided during this project:

- along the P prong: prototypes and final product,

- along the $\mathrm{N}$ prong: alternatives and final architecture of the network.

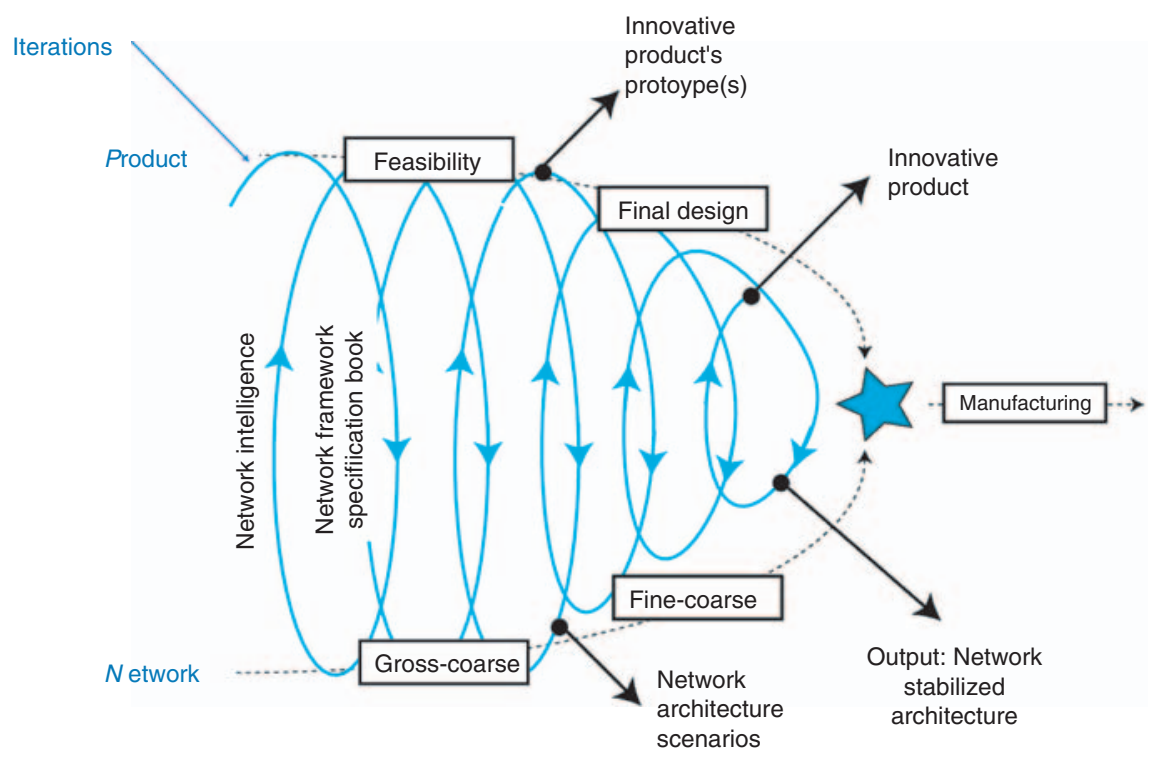

Figure 7. The spiral $\mathrm{P}-\mathrm{N}$ co-design project life cycle. 
Note that $Z=\{\zeta\}$, the set of necessary network constraints to take into account during the product design phase. More intuitive constraints coming from the product development process toward network design activities are noted $\Delta=\{\delta\}$.

To fix the idea of necessary synchronization between $\mathrm{N}$ and $\mathrm{P}$ prongs, simply consider that the product design is composed of two activities: feasibility and final design phases.

\subsection{Feasibility Phase and Gross-coarse Phase}

The feasibility phase defines various technological solutions and seeks to combine all possible building blocks into several global solutions or prototypes (system level design according to Ulrich). During this phase, thinking about technological solutions should allow engineers to conduct network design team towards a selection of potential partners. The needs determined by the feasibility engineers should be gathered into a first set of specifications for the network architecture. It should contain needed inputs, technology, knowledge, or support resources to procure. Based on these specifications, the network designers can search for various scenarios of the network. At this stage, it is not possible to define networking scenarios (the way that the network would run) because of numerous unknown data and important uncertainties. The network design team should identify and contact the most appropriate potential partner. Usable methods are not focused on for the comparison of potential partners. Interested readers may refer to Huang [32] for an example of these techniques. Results of these negotiations must be available for the product concept developers as soon as possible in order to avoid any useless product development. It means that product designers will know any orientation in terms of partners' selection.

An important issue for the definition of the logical specifications book is to represent, when possible, various dependencies between partners and their know-how. These dependences can be modeled by oriented graphs and easily translated by simulating models of the network for future dynamic simulations.

The identification of these dependencies is done using technical data (even though they are not all already fixed) of the innovative product. These technical data, bill-of-materials, and routings are combined together in a mixed technical-data where activities (routings) and parts (bill-of-materials) can be found at the same time. Figure 8 shows a simplified version of this formalism. It contains supplied parts, produced parts, internal activities, and external activities. This formalism models the building blocks of the product within its architecture (see Section 4).

The dependency between partners can be extracted from this formalism, for instance, for two partners $k$ and $m$ at the bottom of the figure. Their dependency can be formulated as follows: the partner $k$ should know constraints of the partner $m$ in order to ease as much as possible its activity and the partner $m$ should be able to assemble or add its activity or design solution on the result of the partner $k$.

This formalism is used to determine the draft global architecture of the network and pose various co-working performance indicators for partners.

Once the network architecture scenarios are defined, the network design team should analyze them according to discussions with partners. The outputs of these activities will increase the market intelligence of the FC. The results of these analyses are then given to product designers in order to improve or stabilize the product design.

In short, $\Delta$ constraints are formalized mainly by the first and definitive network specifications books while $Z$ constraints are represented by the market intelligence and results of the analysis of network and networking scenarios.

The final outputs of this first set of iterations are: (a) one or several product prototypes and (b) one or several scenarios of the network architecture.

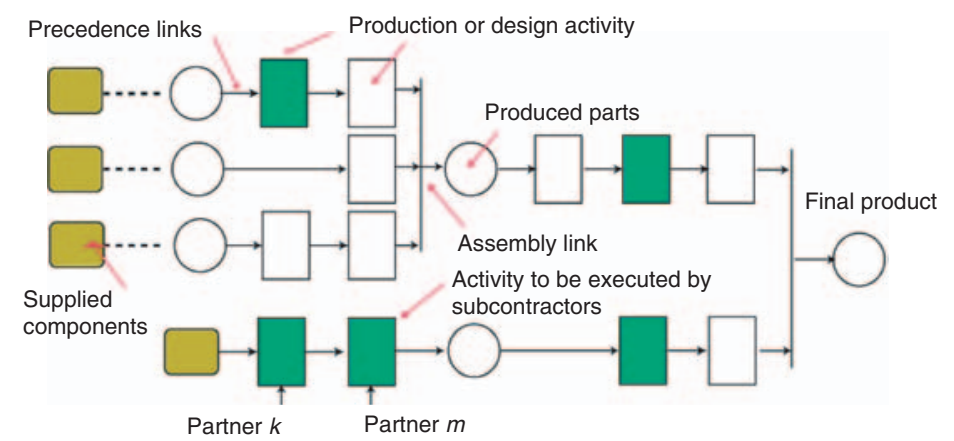

Figure 8. The mixed technical-data formalism. 


\subsection{Final Design Phase and Fine-coarse Phase}

The relationships between product designers and network designers remain the same as described in the previous section. Product designers determine the definitive network architecture specifications book according to all design decisions made jointly by the FC and its critical partners, iteration after iteration.

Final design decisions concern all data that define completely the innovative product (formed by quantifiable properties of products, such as geometry, kinematics, mechanical, and so on).

The target of network designers here is to stabilize architecture alternatives and to gather as much dynamic macro-data as possible. They will be able then to define the network management macro-parameters. These macro-parameters correspond to the framework of products and data exchanges with appropriate attributes. Products exchanges framework between partners contains elements such as delivery delays, lot-sizing data, cost, and quality, while data exchanges framework corresponds to data-sharing characteristics, such as forecasts availability and load and capacity.

\subsection{Functional Description of Supervisory and Control of P-N Co-design}

The past sections define activities that should be executed in harmony. To do so, a two-level control system is suggested.

Network Design Controller and Supervisor (NDS). To co-ordinate decisions and activities related to the network definition and its runs, the establishment of a conceptual entity called NDS is recommended. It will then correspond to an organizational entity in reality (for example the network design team cited before) because it should solve problems linked to strategic, tactical, and especially day-by-day networking actions.

The NDS executes at least the following activities: potential critical partners identification, partners selection, network configuration definition, contracts negotiations. These decisions are guided by $\Delta$ constraints. Planning, optimization of the networking parameters, and control of networking represent the most important tasks of the NDS during fine-coarse design phase.

Collaborative product design controller and supervisor $(C D S)$. As for the network design activities, CDS is considered to be an organizational entity which is in charge of the control of product designers. Other low-level design management tasks will be performed by CDS too.

Co-ordination controller and supervisor. Finally, a control entity is referred to, which takes account of various product-oriented and network-oriented parameters, as the product-network design co-ordination space (CS). The CS controls and manages both activities of collaborative product design process and those of network design. Therefore, from a functional point of view, the CS will work with the NDS and the CDS in a closed-loop structure ( $c f$. Figure 9).

Basically the CS uses business strategic objectives, feedbacks from both network and product design activities and

- the $\Delta$ constraints to prepare product design framework, - the $Z$ constraints to define network design framework.

\section{Discussion, Conclusions, and Further Works}

The $\mathrm{P}-\mathrm{N}$ co-design can represent another efficiency roadmap if correctly thought and managed.

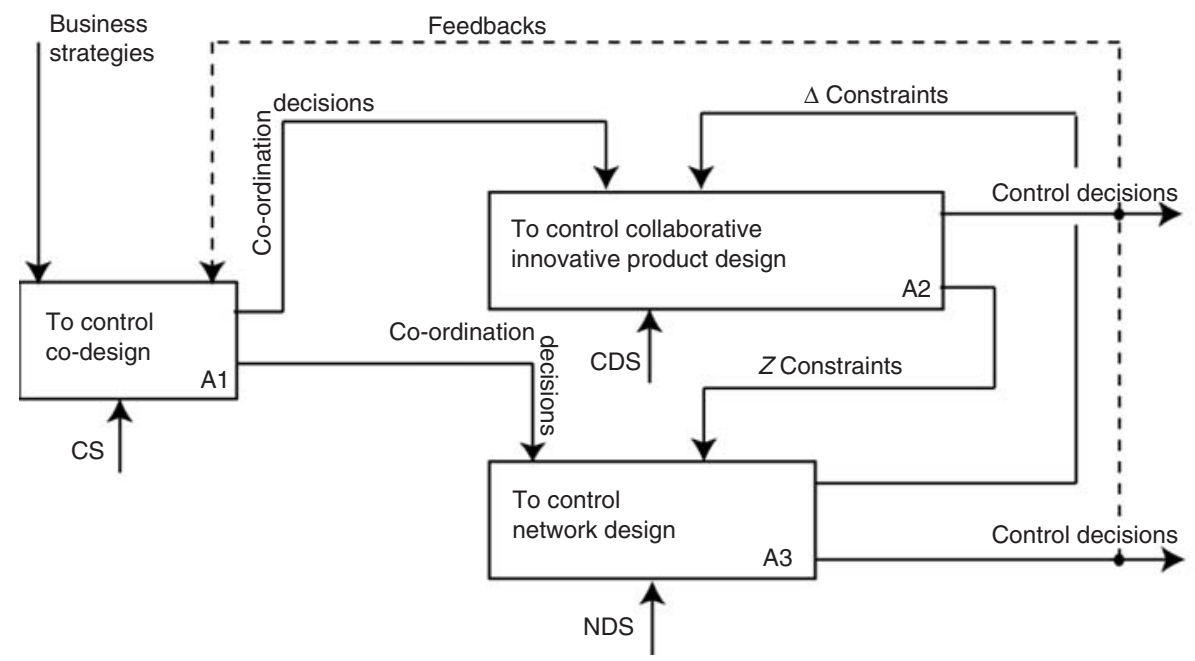

Figure 9. The mixed technical-data formalism. 
Real engagement of material, technology, and service providers should be managed as soon as possible within the product development project. The FC's partners have to be identified and their functionality synchronized largely in advance. The choice of in-house made building blocks and those blocks that should be designed and manufactured outside has to be made based on a clear knowledge of the market and the partners' possibility. Somehow, it means that no such decision can be made without an understanding of the external environment of the FC. These are the main ideas developed here.

In this article, the very first elements of dependency between these two major design processes are shown and modeled. Constraints which connect the product and network design activities are identified, modeled, and described. The way by which these constraints are transferred from one activity to another is formalized through specifications books.

Obviously, the work is just at the beginning. Reference models of functional and technical dependencies between network-product design processes should be determined. These models will allow defining techniques and methodologies to analyze co-operation protocols between partners. Moreover, by introducing a structured approach, it will be possible to control the whole co-working project of the FC as soon as the first collaboration decisions are made.

Porter [33] defined two distinguished ways to act for the future of a firm: strategic positioning (performing different activities from rivals' or performing similar activities in different ways), and gaining operational effectiveness (performing similar activities better than rivals perform them.) which corresponds to 'Do the same things other but better'.

Based on these definitions, it is thought that the co-design can be seen as a powerful technique of strategic positioning and a powerful roadmap for operational efficiency. Indeed, by considering at the early stages of any collaboration all manufacturing and networking constraints, the company could be able to:

- prepare the necessary logistic infrastructure for product and data exchanges.

- negotiate with potential partners, using estimated parameters of collaboration (volume, frequency, protocols...).

- construct a partnership, as win-win like as possible, which develops partner's loyalty.

- organize the network for effective networking.

- develop innovative products according to costquality-delay and profitability period.

- eradicate useless tasks as much as possible.

Thinking according to the co-design paradigm could help companies to define a technique of strategic positioning. This strategic positioning is an objective of the FC first. But, it becomes a larger problem due to the collaboration with others.

The arguments of Charles H. Fine, his numerous examples, and the brief survey of the scientific literature presented, besides the exploratory results developed in this study demonstrate that the co-design could represent a real efficiency niche.

From the authors point of view, several research themes are the most important ones in the near future:

1. The fine-tune modeling of the interactions between network design and product design in the SPIN framework.

2. The identification of methods/tools aiming at the evaluation and the choice of the most relevant partners from the whole set of potential ones.

3. The identification of methods/tools for the assessment of the network's architectures. This is the logical evaluation of various scenarios. For this issue, techniques such as dimensional analysis [34] seem to be quite relevant.

4. The determination of a toolbox for the assessment of the dynamic networking analysis. For this issue the system dynamic concepts may be used.

\section{References}

1. Arend, R. (2006). Implications for Including Shared Strategic Control in Multi-party Relationship Models, European Management Journal, 24(1): 38-48.

2. Johnson, G., Scholes, K., Whittington, R. and Fréry, F. (2005). Stratégique (Translated from Exploring Corporate Strategy), 7th edn, Paris, Pearson Education France.

3. Hax, A.C. and Majluf, N.S. (1991). The Strategy Concept and Process, New Jersey 07632: Prentice Hall: Englewood Cliffs.

4. Fine, Ch.H. (1998). Clockspeed, Winning Industry Control in the Age of Temporary Advantage, Sloan School of Management, Reading, Massachusetts: Perseus Books.

5. Ottosson, S. (2004). Dynamic Product Development DPD, Technovation, 24(3): 207-217.

6. Beamon, B. (1998). Supply Chain Design and Analysis: Models and Methods, International Journal of Production Economics, 55: 281-294.

7. Ballou, R., Gilbert, S. and Mukherjee, A. (2000). New Managerial Challenges from Supply Chain Opportunities, Industrial Marketing Management, 29: 7-18.

8. Cakravastia, A., Toha, I. and Nakamura, N. (2002). A Two-stage Model for the Design of Supply Chain Networks, International Journal of Production Economics, 80(3): 231-248.

9. Goetschalckx, M., Vidal, C. and Dogan, K. (2002). Modelling and Design of Global Logistics Systems: A Review of Integrated Strategic and Tactical Models and Design Algorithms, Eur. J. Operational Research, 143: 1-18. 
10. Guillen, G., Mele, F., Bagajewicz, M., Espuna, A. and Puigjaner, L. (2005). Multiobjective Supply Chain Design under Uncertainty, Chemical Engineering Science, 60(6): 1535-1553.

11. Gunasekaran, A. and Ngai, E. (2005). Build-to-order Supply Chain Management: A Literature Review and Framework for Development, J. Operations Management, 23(5): 423-451.

12. Garg, A. (1999). An Application of Designing Products and Processes for Supply Chain Management, IIE Transactions, 31(5): 417-429.

13. Wang, G., Huang, S. and Dismukes, J. (2005). Manufacturing Supply Chain Design and Evaluation, Int. J. Advance Manufacturing Technology, 25(2): 93-100.

14. Geunes, J. and Pardalos, P. (2003). Network Optimisation in Supply Chain Management and Financial Engineering: An Annotated Bibliography, NETWORKS, 42(2): 66-84.

15. Hicks, C., McGovern, T. and Earl, C. (2000). Supply Chain Management: A Strategic Issue in Engineer to Order Manufacturing, Int. J. Production Economics, 65(2): 179-190.

16. Harrison, T. (2001). Global Supply Chain Design, Information Systems Frontiers, 3(4): 413-416.

17. Mintzberg, H., Lampel, J. and Ahlstrand, B. (1998). Strategy Safari: A Guided Tour through the Wilds of Strategic Management, New York and Hemel Hempstead: Free Press and Prentice Hall Europe.

18. Wang, F., Mills, J. and Devarajan, V. (2002). A Conceptual Approach Managing Design Resource, Computers in Industry, 47: 169-183.

19. Love, T. (2000). Philosophy of Design: A Metatheoretical Structure for Design Theory, Design Studies, 21(3): 293-313.

20. Perrin, J. (1999). Pilotage et evaluation des processus de conception, L'Harttman edition, Janvier.

21. Pahl, G. and Beitz, W. (1996). Engineering Design, A Systematic Approach, 2nd edn, Berlin: Springer.

22. Blessing, L. (1994). A Process-based Approach to Computer Supported Engineering Design, Ph.D. Thesis, University of Twente, Enschende, The Netherlands.

23. Reiner, G. and Trcka, M. (2004). Customized Supply Chain Design: Problems and Alternatives for a Production Company in the Food Industry. A Simulation Based Analysis, Int. J. Production Economics, 89(2): 217-229.

24. Brissaud, D. and Garro, O. (1996). An Approach to Concurrent Engineering Using Distributed Design Methodology, 4(3): 303-311.

25. Hacker, W. (1997). Improving Engineering Design Contributions of Cognitive Ergonomics, Ergonomics, 40(10): 1088-1096.

26. Buccarelli, L. (1988). An Ethnographic Perspective on Engineering Design, Design Studies, 9(3): 1753-1786.

27. Hatchuel, A., Lemasson, P. and Weil, B. (2006). Building Innovation Capabilities: The Development of DesignOriented Organizations, In: Hage, J. (ed.), Innovation, Science, and Institutional Change, Marius Meeus: Oxford University Press.

28. Ullman, D. (1992). The Mechanical Design Process, New York: McGraw-Hill.
29. Ullrich, K. and Eppinger, S. (2003). Product Design and Development, New York: McGraw Hill.

30. Vonderembsea, M.A., Uppalb, M., Huangc, H.H. and Dismukes, J.P. (2006). Designing Supply Chains: Towards Theory Development, Int. J. Production Economics, 100(2): 223-238.

31. Fisher, M.L. (1997). What is the Right Supply Chain for your Product? Harvard Business Review, March-April, 75(2): 105-116.

32. Huang, G.Q., Mak, K.L. and Humphreys, P.K. (2003). A New Model of the Customer-Supplier Partnership in New Product Development, Journal of Materials Processing Technology, 138(1): 301-305.

33. Porter, M.E. (1996). What is Strategy? Harvard Business Review, November-December, 74(6): 61-78.

34. Sonin, A.A. (2001). The Physical Basis of Dimensional Analysis, 2nd edn, MIT, Department of Mechanical Engineering.

\section{Dr Marc Zolghadri}

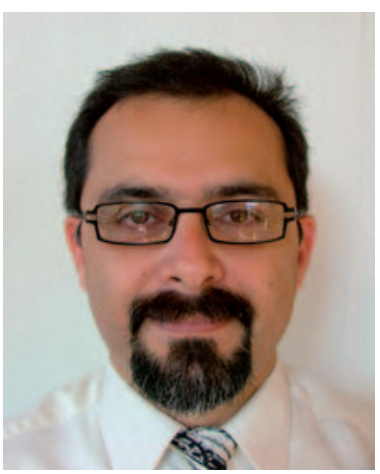

Marc Zolghadri is an associate Professor at the Bordeaux 1 University. He received his $\mathrm{PhD}$ degree in 1998 in the field of data aggregation for the control and supervision of the network of firms. His research interests include product development, co-design of products and network of partners, design of extended product, data aggregation and system control, and supervision.

\section{Dr Claude Baron}

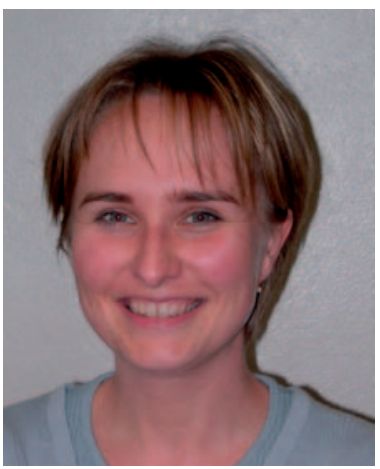

Claude Baron is currently Associate Professor in the National Institute of Applied Sciences Toulouse (France). She received her $\mathrm{PhD}$ degree in Industrial Control from the same institute in 1995. She has published 16 journal papers. Her research interests include product development project, engineering design, and real-time security. 


\section{Dr Philippe Girard}

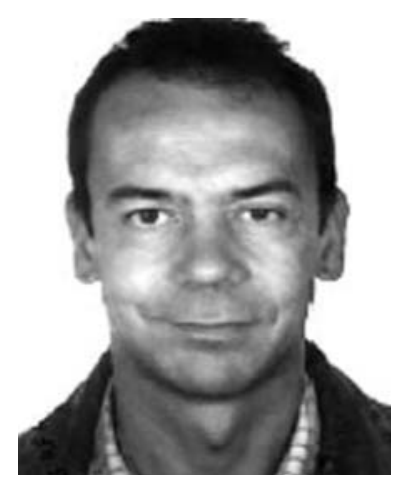

Ph Girard is Professor at the University of Bordeaux (France) and a member of IMS laboratory. After teaching at the University Bordeaux for 10 years, he started his research activity in 1993. He received his PhD degree in 1999 and became professor in 2005. His research interests include co-ordination of engineering design, product and process modeling, performance evaluation, and development of multiagent systems to assist designers. He has published more than 70 papers for conferences, journals and books. He is in charge of the 'Engineering Design' research team at the IMS laboratory, University of Bordeaux, (France). 